\title{
SUPERAÇÃO DA DORMÊNCIA EM SEMENTES DE PAINEIRA-BRANCA
}

\author{
Irinaldo Lima do Nascimento ${ }^{1}$
}

(recebido: 29 de setembro de 2009; aceito: 22 de dezembro de 2011)

RESUMO: A paineira-branca Ceiba glaziovi (kuntze) k. Schu, pertencente à família das Bombacaceas, conhecida como barriguda, é bastante utilizada em paisagismo e reflorestamento, porém a dormência de suas sementes compromete a reprodução da espécie. Objetivou-se, com este trabalho, avaliar a eficácia de diferentes métodos de superação de dormência na germinação. Os tratamentos foram: escarificação mecânica com lixa d'água número 85 , escarificação química com ácido sulfúrico concentrado durante $5,10,15$ e 20 minutos, escarificação física com água quente a $60,70,80$ e $90^{\circ} \mathrm{C}$ durante um minuto; embebição em água destilada, durante 24,48 e 72 horas, aquecimento em estufa de $65^{\circ} \mathrm{C}$ por 1,2, 3 e 4 horas e testemunha. Cada tratamento contou com quatro repetições de 25 sementes, o delineamento experimental foi o inteiramente casualisado e, na comparação de médias, utilizou-se o teste de Skott Knott a 5\% de probabilidade. Os parâmetros avaliados foram porcentagem de emergência, índice de velocidade de emergência, matéria seca e comprimento de plantas. Os tratamentos mais indicados foram: a escarificação mecânica, imersão em ácido sulfúrico pelos tempos de 5, 10 e 15 minutos e imersão em água destilada por 48 horas.

Palavras-chave: Emergência, tratamentos pré-germinativos, vigor, Ceiba glaziovi.

\section{OVERCOMING DORMANCY IN SEEDS OF COTTON-SILK TREE}

\begin{abstract}
Cotton-silk tree Ceiba glaziovii (kuntze) $k$. Schu belongs to family Bombacaceas and is locally known as barriguda. It is widely used in landscaping and reforestation, neverdeless seed dormancy affects reproduction in this species. The objective of this study was to evaluate the effectiveness of different methods to overcome dormancy in the germination process. Treatments included mechanical scarification with 85-grit sandpaper, chemical scarification with concentrated sulfuric acid for 5, 10, 15 and 20 minutes, physical scarification with hot water at $60^{\circ}, 70^{\circ}, 80^{\circ}$ and $90^{\circ} \mathrm{C}$ for one minute, imbibition in distilled water for 24,48 and 72 hours, oven heating at $65^{\circ} \mathrm{C}$ for 1, 2, 3 and 4 hours, and a control treatment. Each treatment included four replicates of 25 seeds, using a completely randomized experimental design, and means were compared by the Scott-Knott test at the 5\% probability level. Assessed parameters included emergence percentage, emergence rate index, dry matter and length of plants. The most recommended treatments were mechanical scarification, immersion in sulfuric acid for 5, 10 and 15 minutes and immersion in distilled water for 48 hours.
\end{abstract}

Key words: Emergence, pre-germination treatments, vigor, Ceiba glaziovii.

\section{INTRODUÇÃO}

A paineira-branca Ceiba glaziovii (kuntze) k. Schum, da família das bombacáceas possui vários nomes populares como barriguda e paineira, tem maior ocorrência e amplitude ecológica restrita ao Nordeste brasileiro, tendo sido encontrada nos estados do Ceará, Paraíba, Pernambuco e Bahia. Geralmente, distribuem-se sobre a caatinga e em áreas de relevo, na caatinga arbórea do vale do rio são Francisco ou sobre serras, também na vegetação de transição entre caatinga e florestas Montana, no Ceará (BOCAGE; SALES, 2002).

A espécie é uma árvore de 6-18m de altura, com copa ampla e bastante ramificada, possui um tronco bem característico por sua intumescência à meia altura com um metro de diâmetro e sua casca cinza-claro é dotada de grande número de acúleos cônicos com até cinco centímetros de comprimento. Os ramos também são providos de acúleos rígidos, as folhas são palmati- compostas com quatro a sete folíolos, possui flores brancas uma a três por nó, em inflorescências terminais. $\mathrm{O}$ fruto é uma cápsula elipsóide, deiscente, glabra, coriácea, contendo muitas sementes pequenas (seis milímetro aproximadamente), de cor marrom-escura, redonda, envoltas por pelos finíssimos, com consistência sedosa, chamada de lã de barriguda que favorecem a dispersão das sementes à grande distância (MAIA, 2004).

$\mathrm{O}$ estudo dessas plantas tornou-se importantes na propagação da espécie, assim como no reflorestamento em regiões secas. A paina retirada de seus frutos pode ser utilizada e comercializada no enchimento de colchões e travesseiros. Por se tratar de uma árvore de grande porte também é utilizada em paisagismo de locais amplos (LORENZI, 1992).

A execução de estudos sobre a propagação da espécie pode ser comprometida, em decorrência da dormência das sementes, pois dificulta a obtenção de estandes com plantas uniformes (CARMONA, 1992).

\footnotetext{
${ }^{1}$ Agrônomo, Mestrando em Fitotecnia - Universidade Federal Rural do Semiárido - BR 110, Km 47, Pres. Costa e Silva - 59625-000 - Mossoro, RN, Brasil-iririlima@hotmail.com
}

Cerne, Lavras, v. 18, n. 2, p. 285-291, abr./jun. 2012 
Dentre as principais causas da dormência, na maioria das espécies, destaca-se a impermeabilidade do tegumento à água, pela formação de uma camada paliçádica de microsclereídeos impregnadas com suberina, cutina e lignina, de pouca afinidade com a água e mucilagens na testa, no pericarpo ou membrana nuclear, sendo este o mecanismo de dormência mais comum entre as espécies da família das Fabaceae (CARVALHO; NAKAGAWA, 2000).

A germinação de sementes, em geral, é uma sequência de eventos metabólicos que resulta na formação da plântula e a baixa porcentagem de germinação pode ser resultante de problemas provenientes de fatores intrínsecos às sementes com baixo vigor e baixa longevidade (MENDONÇA et al., 2000). Em muitas espécies florestais, a dormência das sementes é comum em condições naturais, servindo como mecanismo de sobrevivência da espécie (PIRES et al., 2009); no entanto, torna-se um problema quando as sementes são utilizadas para produção de mudas em larga escala, tanto de regeneração natural como em viveiro (PESKE; BARROS, 2006).

Sementes de algumas espécies arbóreas nativas apresentam baixo índice de emergência, mesmo mantidas em condições de umidade e temperaturas favoráveis, por apresentarem um mecanismo chamado de dureza tegumentar, com elevado grau de impermeabilidade, resultando no atraso da germinação e na desigualdade na emergência das plântulas (MARCOS FILHO, 2005).

Em laboratório, têm sido utilizadas várias metodologias para a quebra de dormência tegumentar, como a escarificação mecânica e química, a embebição das sementes em água destilada e tratamento com altas temperaturas sob condições úmidas e secas (BRASIL, 2009).

O trabalho foi desenvolvido com o objetivo de avaliar os efeitos de diferentes métodos de superação de dormência sobre a germinação em sementes de Ceiba glaziovii (kuntze) k. Schum.

\section{MATERIAL E MÉTODOS}

O trabalho foi desenvolvido no laboratório de análises de sementes da Universidade Federal da Paraíba (UFPB), Campus $\Pi$, na cidade de Areia - PB, utilizandose sementes de Ceiba glaziovii (KUNTZE) k. Schum. As sementes foram colhidas no mês de novembro de 2006, de duas matrizes localizadas no campus de universidade, beneficiadas manualmente e armazenadas em sacos plásticos por quatro dias, a temperatura ambiente de aproximadamente $25^{\circ} \mathrm{C}$ e umidade reativa do ar de 60 a $80 \%$. Após a limpeza e beneficiamento foram submetidos aos tratamentos com a escarificação química, física e mecânica.

Os tratamentos para superação da dormência foram: (1) escarificação mecânica com lixa, esfregandose manualmente as sementes entre duas lâminas de lixas d'água número 85 ; (2) a escarificação química, com ácido sulfúrico concentrado, com imersão das sementes durante $5,10,15$ e 20 minutos; (3) escarificação física com imersão das sementes em um béquer com água quente sobre uma placa aquecedora a $60,70,80$ e $90{ }^{\circ} \mathrm{C}$ durante um minuto; posteriormente, as sementes foram secas e/ou resfriadas à sombra e temperatura ambiente; (4) embebição em água destilada em béquer, durante 24 , 48 e 72 horas; (5) aquecimento em estufa de $65^{\circ} \mathrm{C}$ por $1,2,3,4$ horas respectivamente e (6) testemunha (sem qualquer tratamento).

O delineamento experimental utilizado foi o inteiramente casualizado, com 17 tratamentos separadamente. As parcelas foram constituídas por 100 sementes, cada experimento consta de quatro repetições de 25 sementes.

Após a exposição das sementes aos diferentes tratamentos pré-germinativos, as mesmas foram submetidas aos testes de germinação e emergência, sendo distribuídas em bandejas de polietileno de forma equidistante, com um centímetro de profundidade, usando-se como substrato para germinação areia altoclavada, sendo umedecidas duas vezes por dia, em casa de vegetação com temperatura variando de 24 a $32{ }^{\circ} \mathrm{C}$ e umidade de 60 a $80 \%$.

A germinação das sementes foi monitorada diariamente por 30 dias e foram consideradas germinadas as sementes que romperam o tegumento no sentido fototrópico positivo, com emissão do eixo embrionário. A análise de variância pelo teste $\mathrm{F}$, com o uso do delineamento inteiramente casualizado, foi utilizada para avaliar o efeito dos tratamentos sobre as variáveis; posteriormente, os dados foram transformados em $\operatorname{Arcsen} \sqrt{x / 100}$, conforme Steel e Torrie (1980), para posterior comparação das médias pelo o teste de Scott Knott, a 5\% de probabilidade.

Avaliou-se: (a) o número de sementes germinadas, durante 30 dias pela determinação da porcentagem de germinação; (b) o índice de velocidade de emergência (IVE), segundo Maguire (1962); (c) comprimento da raiz e da parte aérea das plântulas normais, realizado por meio da média aritmética como medida de posição, utilizando-se o teste de Scott Knott a 5\% de probabilidade; (d) por último, a massa seca, calculada pela relação entre o peso seco e o número de plantas germinadas, por repetição, utilizandose também o teste de Scott-Knott a 5\% de probabilidade.

Cerne, Lavras, v. 18, n. 2, p. 285-291, abr./jun. 2012 


\section{RESULTADOS E DISCUSSÃO}

Entre todos os métodos testados para promover a superação da dormência em sementes de Ceiba glaziovii, constatou-se que o uso de ácido sulfúrico concentrado com exposição das sementes durante 10, 15, 20 minutos respectivamente e a escarificação com lixa e imersão em água por 48 horas proporcionaram maior emergência em relação aos demais tratamentos (Figura 1). Dentre os métodos menos eficazes na quebra de dormência para essa espécie, a água aquecida a $80^{\circ} \mathrm{C}$ e a $90^{\circ} \mathrm{C}$ aparece com valores menores que o tratamento controle, sendo justificado em razão do excesso de temperatura que pode levar a uma indução de uma dormência secundária ou, até mesmo, à morte ou dano do embrião.

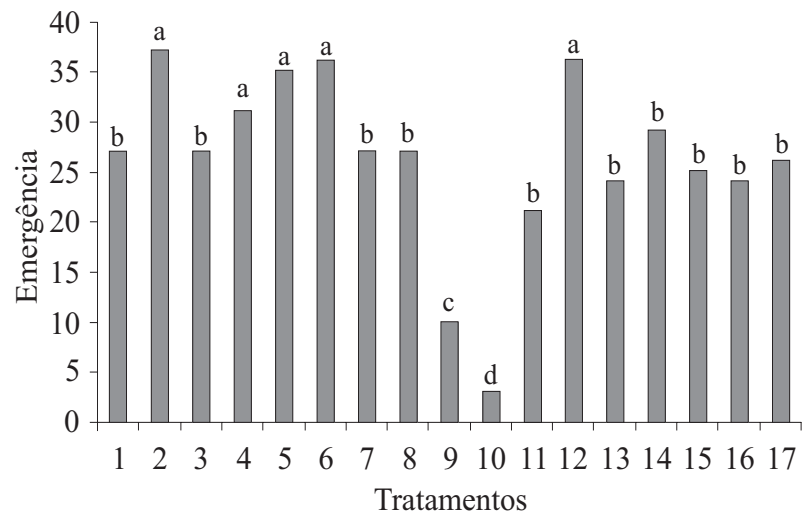

1-testemunha; 2- lixa d'água; 3- imersão em ácido sulfúrico por 5 minutos; 4-imersão em ácido sulfúrico por 10 minutos; 5-imersão em ácido sulfúrico por 15 minutos; 6-imersão em ácido sulfúrico por 20 minutos; 7-imersão em água quente a $60^{\circ} \mathrm{C} ; 8$-imersão em água quente por $70^{\circ} \mathrm{C}$; 9-imersão em água quente por $80^{\circ} \mathrm{C}$; 10 -imersão em água quente por $90^{\circ} \mathrm{C}$; 11-imersão em água destilada por 24 horas; 12 -imersão em água destilada por 48 horas; 13 -imersão em água destilada por 72 horas; 14-aquecimento em estufa por 1 horas; 15 -aquecimento em estufa por 2 horas; 16 -aquecimento em estufa por 3 horas; 17-aquecimento em estufa por 4 horas.

Legenda: Médias acompanhadas com a mesma letra não diferem estatisticamente entre si.

Figura 1 - Percentagem média de germinação $(G)$ das sementes de Ceiba glaziovi (kuntze) k. Schun pelo teste de média Scott-Knott, ao nível de 5\% de significância, após um mês de observação. CV de 16,20.

Figure 1 - Mean germination percentage $(G)$ of seeds of Ceiba glaziovii (kuntze) $k$. Schum by the Scott-Knott test at the 5\% significance level, after one month of observation. CV of 16.20.
Observa-se que, com apenas cinco minutos de exposição ao acido sulfúrico, não houve tempo o suficiente de degradar o tegumento; à medida que esse tempo aumentou a degradação foi sendo efetuada. Pacheco e Matos (2009), trabalhando com sementes de Apeiba tibourbou Aubl., observaram que a imersão em ácido sulfúrico por apenas um minutos foi o suficiente para a quebra da dormência tegumentar da espécie, quando aumentou-se o tempo de exposição ao ácido a germinação reduziu cerca de setenta por cento.

O tempo de imersão em ácido sulfúrico varia com a espécie, segundo Previero et al. (1996) as sementes de Panicum maximum necessitam de apenas cinco minutos de imersão em ácido para germinarem, sementes de Bixa orellana precisam de 15 a 20 minutos de ácido sulfúrico (AMARAL et al., 1995), sementes de Bauhinia monadra devem passar por 20 minutos de ácido sulfúrico para germinar (ALVES et al., 2000), sementes de Styllosanthes guianensis só germinam quando tratadas com ácido sulfúrico por cinco minutos (ARAÚJO et al., 1996), já, em Acacia tortilis, a escarificação com ácido sulfúrico $50 \%$ por 40-50 minutos é o suficiente para eliminar a dormência (JOKER, 2000).

O tratamento com escarificação mecânica com lixa d'água também se mostrou propicio à germinação de Ceiba glaziovii, da mesma forma a eficiência da escarificação mecânica foi verificada em Casalpinea ferrea, Cássia grandis e Samanea saman (LOPES et al., 2003); e Bauhinia ungulata L. (ALVES et al., 2000). Para esses autores, os resultados podem ser explicados pela ocorrência de injúrias nas sementes provocadas pela fricção mecânica ou pela diferença de constituição do tegumento de diferentes espécies de sementes.

Analisando o IVE (Figura 2) resultados semelhantes ao de emergência com os tratamentos ácido sulfúrico por 10,15 e 20 minutos, escarificação com lixa e imersão em água destilada por 48 horas foram comprovados. $\mathrm{O}$ uso de ácido sulfúrico como método de superação de dormência tornou viável, indicando que as sementes germinaram em períodos uniformes. Nesses tratamentos, a alta acidificação provavelmente foi à responsável pelos resultados obtidos, por ter causado a deterioração da camada impermeável das sementes.

Para Ogunwenmo e Ugborogho (1999), o ácido sulfúrico concentrado proporciona alta capacidade de germinação para espécies como Chorisia speciosa, Bombax malabaricum, Ipomoea hederifolia. Possivelmente, o ácido tenha destruído a camada impermeável das

Cerne, Lavras, v. 18, n. 2, p. 285-291, abr./jun. 2012 


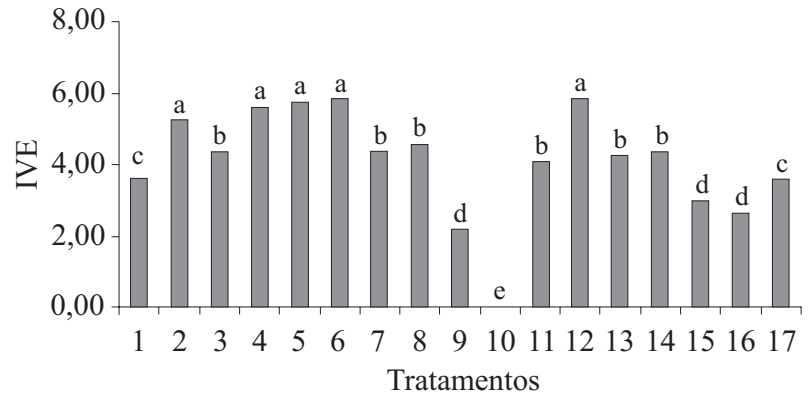

1-testemunha; 2- lixa d'água; 3- imersão em ácido sulfúrico por 5 minutos; 4-imersão em ácido sulfúrico por 10 minutos; 5-imersão em ácido sulfúrico por 15 minutos; 6-imersão em ácido sulfúrico por 20 minutos; 7-imersão em água quente a $60^{\circ} \mathrm{C} ; 8$-imersão em água quente por $70^{\circ} \mathrm{C}$; 9-imersão em água quente por $80^{\circ} \mathrm{C} ; 10$-imersão em água quente por $90^{\circ} \mathrm{C}$; 11-imersão em água destilada por 24 horas; 12-imersão em água destilada por 48 horas; 13 -imersão em água destilada por 72 horas; 14-aquecimento em estufa por 1 horas; 15 -aquecimento em estufa por 2 horas; 16 -aquecimento em estufa por 3 horas; 17-aquecimento em estufa por 4 horas.

Legenda: Médias acompanhadas com a mesma letra não diferem estatisticamente entre si.

Figura 2 - Percentagem média de índice de velocidade de emergência (IVE) das sementes de Ceiba glaziovi (kuntze) k. Schun pelo teste de média a nível de $5 \%$ de significância agrupado pelo teste de Scott-Knott, após um mês de observação. CV de 12,47 .

Figure 2 - Mean percentage of emergence rate index (IVE) of seeds of Ceiba glaziovii (kuntze) $k$. Schum by the mean test at the 5\% significance level as grouped by the Scott-Knott test, after one month of observation. CV of 12.47.

sementes sem causar danos ao embrião, proporcionando germinação mais eficiente e rápida, assim como os demais tratamentos citados. Botenho et al. (2010), trabalhando com sementes de Schinopsis brasiliensis Engl., observaram melhores índices de velocidade de germinação, utilizando ácido sulfúrico por 30 minutos. Sampaio et al. (2001) constataram maior velocidade de emergência das plântulas de Boudichia virgiloides H.B.K. quando as sementes ficaram imersas no ácido por períodos entre 8 e 11 minutos.

A escarificação mecânica e a embebição em água destilada são outros métodos que possibilitam a quebra da dormência e o crescimento e desenvolvimento das plântulas. Ferreira e Santos (2009) com a espécie Rollinia mucosa obtiveram resultados satisfatórios, utilizando escarificação com lixa e, em seguida, embebição em água destilada por 24 horas. Já, Tavares et al. (2000) evidenciaram, com sementes de Clitorea ternateu, uma leguminosa tropical, que a escarificação apenas com lixa proporcionou resultados estatisticamente superiores em relação aos tratamentos imersão em ácido sulfúrico (10\%, 40 minutos) e imersão em água quente $\left(100{ }^{\circ} \mathrm{C}\right.$, por 20 minutos). Medeiros Filho et al. (2005), utilizando tratamentos para a quebra da dormência tegumentar de sementes de Caesalpinia ferrea também obtiveram resultados satisfatórios, utilizando a escarificação com lixa.

Nas Figuras 3 e 4, observam-se a porcentagem de massa seca de raiz e parte aérea. Verificou-se que, para a raiz, os melhores resultados foram escarificação com lixa, imersão em ácido sulfúrico por 20 minutos, imersão em água quente a 70 e $80^{\circ} \mathrm{C}$ e imersão em água destilada por 24, 48 e 72 horas e aquecimento em estufa por 1, 2 e 3 horas. Para a massa seca de parte aérea, não houve diferenças estatísticas entre os tratamentos utilizados, e também houve um coeficiente de variação acima da média, indicando uma menor homogeneização dos dados apresentados.

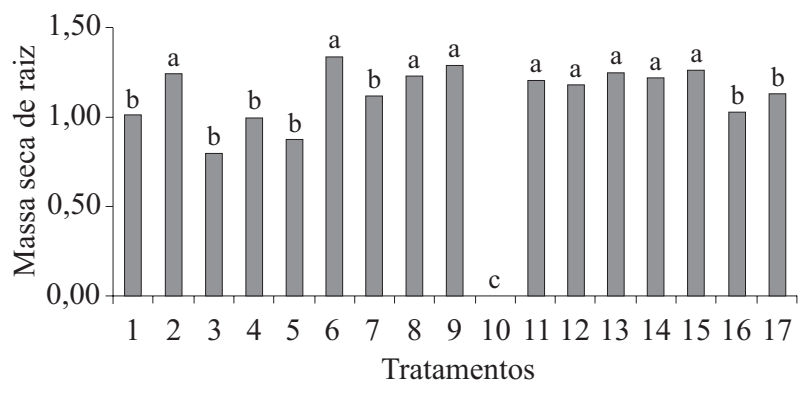

1-testemunha; 2- lixa d'água; 3- imersão em ácido sulfúrico por 5 minutos; 4-imersão em ácido sulfúrico por 10 minutos; 5-imersão em ácido sulfúrico por 15 minutos; 6-imersão em ácido sulfúrico por 20 minutos; 7-imersão em água quente a $60^{\circ} \mathrm{C} ; 8$-imersão em água quente por $70^{\circ} \mathrm{C}$; 9-imersão em água quente por $80^{\circ} \mathrm{C} ; 10$-imersão em água quente por $90^{\circ} \mathrm{C}$; 11-imersão em água destilada por 24 horas; 12 -imersão em água destilada por 48 horas; 13-imersão em água destilada por 72 horas; 14 -aquecimento em estufa por 1 horas; 15 -aquecimento em estufa por 2 horas; 16-aquecimento em estufa por 3 horas; 17-aquecimento em estufa por 4 horas.

Legenda: Médias acompanhadas com a mesma letra não diferem estatisticamente entre si.

Figura 3 - Percentagem média de massa seca da raiz de Ceiba glaziovi (kuntze) k. Schun, pelo teste de média e variância, agrupados pelo teste de Scott-Knott. CV de 17,84.

Figure 3-Mean percentage of root dry matter in Ceiba glaziovii (kuntze) $k$. Schum, by the means and variance test, as grouped by the Scott-Knott test. CV of 17.84 .

Cerne, Lavras, v. 18, n. 2, p. 285-291, abr./jun. 2012 


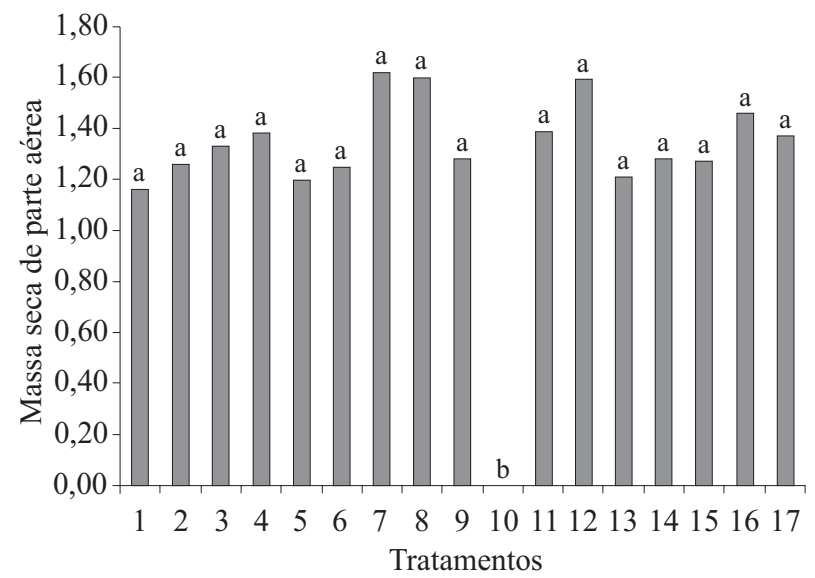

1-testemunha; 2- lixa d'água; 3- imersão em ácido sulfúrico por 5 minutos; 4-imersão em ácido sulfúrico por 10 minutos; 5-imersão em ácido sulfúrico por 15 minutos; 6-imersão em ácido sulfúrico por 20 minutos; 7-imersão em água quente a $60^{\circ} \mathrm{C} ; 8$-imersão em água quente por $70^{\circ} \mathrm{C}$; 9-imersão em água quente por $80^{\circ} \mathrm{C}$; 10 -imersão em água quente por $90^{\circ} \mathrm{C}$; 11-imersão em água destilada por 24 horas; 12 -imersão em água destilada por 48 horas; 13 -imersão em água destilada por 72 horas; 14-aquecimento em estufa por 1 horas; 15 -aquecimento em estufa por 2 horas; 16 -aquecimento em estufa por 3 horas; 17-aquecimento em estufa por 4 horas.

Legenda: Médias acompanhadas com a mesma letra não diferem estatisticamente entre si.

Figura 4 - Percentagem média de massa seca da parte aérea de Ceiba glaziovi (kuntze) k. Schun, pelo teste de média e variância, agrupados pelo teste de Scott-Knott. CV de 36,44.

Figure 4 - Mean percentage of shoot dry matter in Ceiba glaziovii (kuntze) $k$. Schum, by the means and variance test, as grouped by the Scott-Knott test. CV of 36.44 .

Medeiros Filho et al. (2005) verificaram que não houve diferença estatística no peso seco de parte aérea de plântulas de Caesalpinia ferrea em que as sementes foram condicionadas em casa de vegetação e submetidas aos tratamentos de imersão em água destilada por 48 horas, imersão em água a $80^{\circ} \mathrm{C}$ e escarificação mecânica com lixa. Reis et al. (2005), trabalhando com sementes de Operculina macrocarpa e Operculina alata com e sem escarificação e embebição em água destilada por 24 horas, demonstraram que para Operculina macrocarpa não houve diferenças significativas na parte aérea de plântulas, já, na raiz, sementes escarificadas e embebidas promoveram resultados superiores, em Operculina alata a parte aérea se apresentou superior com sementes escarificadas e em raiz, com sementes escarificadas e embebidas.
Na Figura 5, comprimento de parte aérea, as sementes submetidas aos tratamentos testemunha, imersão em água à 80 e $90^{\circ} \mathrm{C}$ respectivamente, promoveram resultados menores que os demais. Na Figura 6, comprimento de raiz, resultados semelhantes foram encontrados onde apenas os tratamentos testemunha, imersão em acido sulfúrico por 5 minutos, imersão em água à 80 e $90^{\circ} \mathrm{C}$ respectivamente e aquecimento em estufa por 1, 2 e 3 horas geraram plântulas com baixos crescimentos.

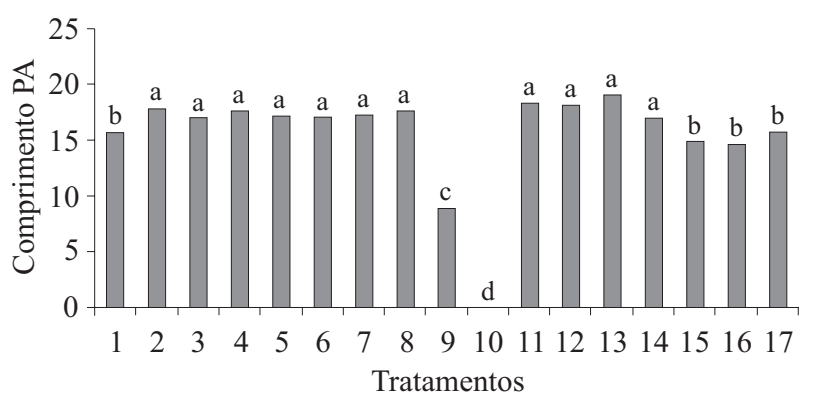

1-testemunha; 2- lixa d'água; 3- imersão em ácido sulfúrico por 5 minutos; 4-imersão em ácido sulfúrico por 10 minutos; 5-imersão em ácido sulfúrico por 15 minutos; 6-imersão em ácido sulfúrico por 20 minutos; 7-imersão em água quente a $60^{\circ} \mathrm{C}$; 8-imersão em água quente por $70^{\circ} \mathrm{C}$; 9-imersão em água quente por $80^{\circ} \mathrm{C} ; 10$-imersão em água quente por $90^{\circ} \mathrm{C}$; 11-imersão em água destilada por 24 horas; 12 -imersão em água destilada por 48 horas; 13-imersão em água destilada por 72 horas; 14-aquecimento em estufa por 1 horas; 15 -aquecimento em estufa por 2 horas; 16-aquecimento em estufa por 3 horas; 17-aquecimento em estufa por 4 horas.

Legenda: Médias acompanhadas com a mesma letra não diferem estatisticamente entre si.

Figura 5 - Comprimento em desenvolvimento da parte aérea de Ceiba glaziovi (kuntze) k. Schun, pelo teste de média e variância, agrupados pelo teste de Scott-Knott .CV de 10,81.

Figure 5-Length of shoot in Ceiba glaziovii (kuntze) $k$. Schum, by the means and variance test, as grouped by the Scott-Knott test. CV of 10.81 .

Pacheco e Matos (2009) observaram resultados semelhantes com sementes de Apeiba tibourbou, que não apresentaram diferença estatística para os parâmetros comprimento de raiz e parte aérea nos tratamentos escarificação mecânica com lixa, choque térmico com sementes não hidratadas, choque térmico com sementes hidratadas, imersão em água a $80^{\circ} \mathrm{C}$ e escarificação química com ácido sulfúrico por 1 e 5 minutos, sendo todos estes superiores à testemunha.

Cerne, Lavras, v. 18, n. 2, p. 285-291, abr./jun. 2012 


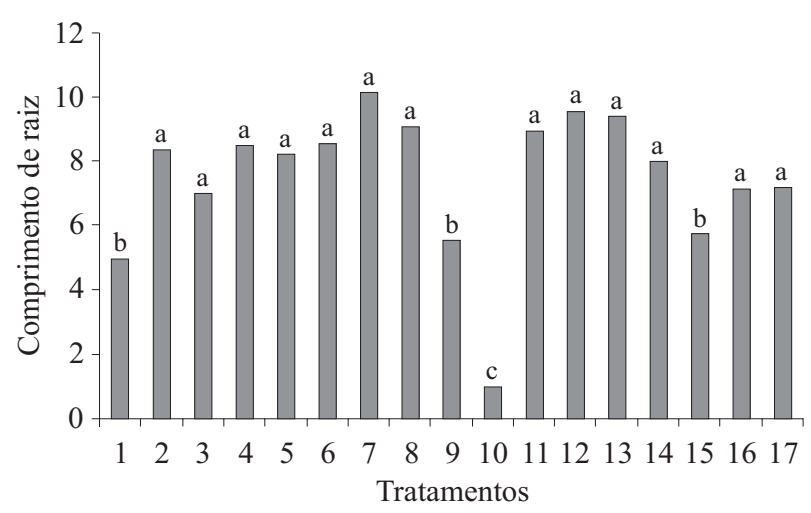

1-testemunha; 2- lixa d'água; 3-imersão em ácido sulfúrico por 5 minutos; 4-imersão em ácido sulfúrico por 10 minutos; 5-imersão em ácido sulfúrico por 15 minutos; 6-imersão em ácido sulfúrico por 20 minutos; 7-imersão em água quente a $60^{\circ} \mathrm{C}$; 8-imersão em água quente por $70^{\circ} \mathrm{C}$; 9-imersão em água quente por $80^{\circ} \mathrm{C}$; 10 -imersão em água quente por $90^{\circ} \mathrm{C}$; 11-imersão em água destilada por 24 horas; 12 -imersão em água destilada por 48 horas; 13 -imersão em água destilada por 72 horas; 14-aquecimento em estufa por 1 horas; 15 -aquecimento em estufa por 2 horas; 16 -aquecimento em estufa por 3 horas; 17-aquecimento em estufa por 4 horas.

Legenda: Médias acompanhadas com a mesma letra não diferem estatisticamente entre si.

Figura 6-Comprimento em desenvolvimento da raiz primaria de Ceiba glaziovi (kuntze) k. Schun, pelo teste de média e variância, agrupado pelo teste de Scott-Knott CV de 6,37.

Figure 6 - Length of primary root in Ceiba glaziovii (kuntze) $k$. Schum, by the means and variance test, as grouped by the Scott-Knott test. CV of 6.37.

Resultados contrários foram encontrados por Ferreira e Santos (2009) em sementes de Rullinia mucosa, não havendo diferença significativa entre a testemunha e os tratamentos lixa e lixa mais embebição em água destilada por 24 horas para comprimento da raiz e parte aérea das plântulas. Gonçalves et al. (2006) obtiveram plântulas de Mimosa caesalpiniaefolia Bent com maior comprimento quando utilizaram a escarificação mecânica, Já, Lima e Garcia (1996) obtiveram maior comprimento em plântulas de Acacia mangium quando as sementes foram submetidas à imersão em água à temperatura de $80^{\circ} \mathrm{C}$.

\section{CONCLUSÃO}

A escarificação mecânica com lixa d'água, imersão em ácido sulfúrico por 10, 15 e 20 minutos e imersão em água destilada por 48 horas são os métodos mais eficientes para a superação da dormência de Ceiba glaziovi (kuntze) k. Schun.

Cerne, Lavras, v. 18, n. 2, p. 285-291, abr./jun. 2012

\section{REFERÊNCIAS}

ALVES, M. C. S.; MEDEIROS-FILHO, S.; ANDRADENETO, M.; TEÓFILO, E. M. Superação da dormência em sementes de Bauhinia monandra Britt. E Bauhinia ungulata L. Caesalpinoideae. Revista Brasileira de Sementes, Brasília, v. 20, p. 131-138, 2000.

AMARAL, L. I. V.; PEREIRA, M. F.; CORTELAZZO, A. L. Quebra de dormência em sementes de Bixa orellana. Revista Brasileira de Fisiologia Vegetal, Londrina, v. 7, p. 151-157, 1995.

ARAÚJO, E. F.; ARAÚJO, C. F.; ARAÚJO, R. F.; GALVÃO, J. C. C.; SILVA, R. F. Efeito da escarificação das sementes e dos frutos de Stylosanlhes guianensis (Aubl) Sw. na germinação.

Revista Brasileira de Sementes, Brasília, v. 18, p. 73-76, 1996.

BOCAGE, A. L. D.; SALES, M. F. A família bombacaceae kunth no estado de Pernambuco, Brasil. Acta Botânica Brasileira, São Paulo, v. 16, n. 2, p. 123-139, 2002.

BRASIL. Ministério da Agricultura. Regras para análise de sementes. Brasília, 2009. 399 p.

CARMONA, R. Problemática e manejo de bancos de sementes de invasoras em solos agrícolas. Planta Daninha, Viçosa, v. 10, n. 1/2, p. 5-16, 1992.

CARVALHO, N. M.; NAKAGAWA, J. Sementes: ciência, tecnologia e produção. 4. ed. Jaboticabal: Funep, 2000. 558 p.

FERREIRA, M. G. R.; SANTOS, M. R. A. Superação de dormência de sementes de biriba (Rollinia mucosa (Jacq.) Baill). Revista Brasileira de Sementes, Brasília, v. 31, n. 4, p. 95-99, 2009.

GONÇALVES, E. P.; ALVES, E. U.; MONALISA, A. Temperatura, beneficiamento e superação de dormência sobre o potencial fisiológico de sementes de sabiá (Mimosa caesalpiniaefolia). Sitientibus Série Ciências Biológicas, Feira de Santana, v. 6, n. 1, p. 45-49, 2006.

JOKER, D. Seed leaflet: Acacia tortilis (Forssk) Hayne. Humlebaek: Danida Forest Seed Centre, 2000. 3 p.

LIMA, D.; GARCIA, L. C. Avaliação de métodos para o teste de germinação em sementes de Acacia mangium Willd. Revista Brasileira de Sementes, Brasília, v. 18, n. 2, p. 180-185, 1996. 
LOPES, J. C.; SILVA, G. F.; POSSE, S. C. P.; RUY, J. Germinação e dormência de sementes de Cassia fistula $\mathrm{L}$. Curitiba: Brasil Florestal, 2003.

LORENZI, H. Árvores brasileiras: manual de identificação e cultivo de plantas arbóreas nativas do Brasil. Nova Odessa: Plantarum, 1992.

MAGUIRE, J. D. Speed of germination and selectionand evolution for seediling emergence and vigor. Crop Science, Madison, v. 1, p. 176-177, 1962.

MAIA, G. N. Catingueira. In: Caatinga: árvores e arbustos e suas utilidades. São Paulo: Leitura de Arte, 2004. p. 159-169.

MARCOS FILHO, J. Fisiologia de sementes de plantas cultivares. Piracicaba: FEALQ, 2005. 495 p.

MEDEIROS FILHO, S.; SILVA, M. A. P.; SANTOS FILHO, M. E. C. Germinação de sementes e desenvolvimento de plântulas de plântulas de Caesalpinia ferrea Mart. Ex Tul var. ferrea em casa de vegetação e germinador. Revista Ciência Agronômica, Fortaleza, v. 36, n. 2, p. 203-208, 2005.

MENDONÇA, E. A. F.; RAMOS, N. P.; FESSEL, S. A.; SADER, R. Teste de deterioração controlada em sementes de brócolis (Brassica olericola) var. italiana. Revista Brasileira de Sementes, Brasília, v. 22, n. 1, p. 280-287, 2000.

OGUNWENMO, K.; UGBOROGHO, R. E. Effects of chemical and mechanical scarification on seed germination of five species of Ipomoea (Convolvulaceae). Boletim da Sociedade Broteriana, Coimbra, v. 69, p. 147-162, 1999.

PACHECO, M. V.; MATOS, V. P. Métodos para superação da dormência tegumentar em sementes de Apeiba tibourdou
Aubl. Revista Brasileira de Ciências Agrárias, Recife, v. 4, p. 62-66, 2009.

PESKE, S. T.; BARROS, A. C. S. A. Sementes: fundamentos científicos e tecnológicos. Pelotas: UFPel, 2006. 454 p.

PIRES, L. A.; CARDOSO, V. J. M.; JOLY, C. A.; RODRIGUES, R. R. Germination of Ocotea pulchella (Nees) $\mathrm{Mez}$ (Lauraceae) seeds in laboratory and natural resting environment conditions. Brazilian Journal of Biology, São Carlos, v. 69, n. 3, p. 935-942, 2009.

PREVIERO, C. A.; MARTINS, L.; FONSECA, R. H. A.; GROTH, D. Efeito dos tratamentos para superação da dormência em sementes de capim - colonião (Panicum maximum Jacq.) durante o armazenamento. Revista Brasileira de Sementes, Brasília, v. 18, p. 143-148, 1996.

REIS, R. G. E.; MOREIRA, F. J. C.; CIDRÃO, S. M.; BEZERRA, A. M. E. Influência da escarificação mecânica e pré-embebição na emergência e crescimento de plântulas de batata-de-purga 'branca' e 'amarela'. In: CONGRESSO BRASILEIRO DE OLERICULTURA, 2005, Fortaleza. Anais... Fortaleza: UFC, 2005. CD-ROM.

SAMPAIO, L. S. V.; PEIXOTO, C. P.; PEIXOTO, M. F. S. P.; COSTA, J. A.; GARRIDO, M. S.; MENDES, L. N. Ácido sulfúrico na superação da dormência de sementes de sucupirapreta (Boudichia virgiloides H.B.K. - Fabaceae). Revista Brasileira de Sementes, Brasília, v. 23, p. 184-190, 2001.

STEEL, R. G.; TORRIE, J. H. Principles and procedures of statistics. 2. ed. New York: McGraw-Hill, 1980. 633 p.

TAVARES, E. M.; DEMINICIS, B. B.; VIEIRA, H. D.; ARAÚJO, S. A. C.; BLUME, M. C.; ALMEIDA, J. C. C.; SANTOS, C. O. Superação da dormência em sementes de Clitorea ternatea L. Brasília: Associação Brasileira de Zootecnistas, 2000.

Cerne, Lavras, v. 18, n. 2, p. 285-291, abr./jun. 2012 